GRASAS Y ACEITES 71 (1)

January-March 2020, e336

ISSN-L: 0017-3495

https://doi.org/10.3989/gya.0938182

\title{
Utilization of unsaponifiable matter from rice bran oil fatty acid distillate for preparing an antioxidant-rich oleogel and evaluation of its properties
}

\author{
S. Sahu ${ }^{\mathrm{a}}$, M. Ghosh ${ }^{\mathrm{a}, \bigotimes}$ and D.K. Bhattacharyya ${ }^{\mathrm{a}}$ \\ ${ }^{a}$ School of Community Science and Technology, Indian Institute of Engineering Science and Technology, Shibpur \\ ${ }^{\square}$ Corresponding author: g_minakshi2000@yahoo.com
}

Submitted: 29 September 2018; Accepted: 19 February 2019; Published online: 13 January 2019

SUMMARY: Rice bran oil fatty acid distillate (RBOFAD) is an important by-product obtained from the physical refining process. This fatty acid distillate contains high a amount of Unsaponifiable Matter ( $\gamma$-oryzanol $3.27 \mathrm{gm} / 100 \mathrm{gm} \mathrm{UM}$; total tocopherol $10.93 \mathrm{mg} / 100 \mathrm{~g} \mathrm{UM}$; total phytosterol $21.81 \mathrm{~g} / 100 \mathrm{~g} \mathrm{UM}$; squalene $1.15 \mathrm{~g} / 100 \mathrm{~g} \mathrm{UM}$ and total fatty alcohol $73.34 \mathrm{~g} / 100 \mathrm{~g} \mathrm{UM}$ ) and free fatty acids. Antioxidant-rich Oleogels were obtained from rice bran wax (RBW), rice bran oil fatty acid distillate (RBOFAD) and refined rice bran oil. The main objective of this study was to utilize the antioxidant-rich unsaponifiable matter of RBOFAD (UMRBOFAD) as an organogelator along with rice bran wax, which also acts as a good organogelator. Antioxidant-rich oleogel was prepared using UMRBFAD, ethylcellulose (EC) and RBW at 2\%, 2\%, 3\% on weight basis, respectively, in refined rice bran oil and this antioxidant-rich oleogel was compared with rice bran oil oleogel using RBW at 7\% on weight basis of rice bran oil. These oleogels were evaluated using a combination of techniques such as differential scanning calorimetry (DSC), polarized light microscopy (PLM), Viscosity, synchrotron radiation X-ray diffraction (SR-XRD) and FTIR Spectroscopy. The differential scanning calorimetry (DSC) measured the thermal properties of rice bran oil oleogel and high antioxidant-rich oleogel. Polarized light microscopy images revealed needle-like crystals for RBW. SR-XRD measurements were used for clarification of the crystal structures of the building blocks of these oleogels. The antioxidant activities of oleogels were evaluated involving DPPH and ABTS assays.

\section{KEYWORDS: Oleogels; RBOFAD; Rice bran oil; Rice bran wax; UMRBOFAD}

RESUMEN: Utilización del insaponificable de destilados de ácidos grasos de aceites de salvado de arroz para la preparación de oleogeles ricos en antioxidantes y evaluación de sus propiedades. El destilado de ácidos grasos de aceites de salvado de arroz (RBOFAD) es un subproducto importante que se obtiene en el proceso de refinación física. Este destilado contiene una gran cantidad de materia insaponificable ( $\gamma$-oryzanol $3.27 \mathrm{~g} / 100 \mathrm{~g} \mathrm{UM}$; tocoferol total $10.93 \mathrm{mg} / 100 \mathrm{~g} \mathrm{UM}$; phytosterol total $21.81 \mathrm{~g} / 100 \mathrm{~g} \mathrm{UM}$; escualeno $1.15 \mathrm{~g} / 100 \mathrm{~g}$ UM y alcohol graso total $73.34 \mathrm{~g} / 100 \mathrm{~g} \mathrm{UM}$ ) y ácidos grasos libres. Los oleogeles ricos en antioxidantes se obtuvieron de la cera del salvado de arroz (RBW), de destilados de ácidos grasos de aceite de salvado de arroz (RBOFAD) y de aceite de salvado de arroz refinado. El objetivo principal de este estudio fue utilizar materia insaponificable de RBOFAD (UMRBOFAD) ricos en antioxidantes como organogelador junto con cera de salvado de arroz que actúa también como un buen organogelador. El oleogel rico en antioxidantes se preparó usando UMRBFAD, etilcelulosa (EC) y RBW al 2\%, 2\%, 3\% en peso respectivamente en aceite de salvado de arroz refinado y este oleogel rico en antioxidantes se comparó con el oleogel de aceite de salvado de arroz usando RBW al 7\% en peso de aceite de salvado de arroz. Estos oleogeles se evaluaron utilizando una combinación de técnicas como la calorimetría 
diferencial de barrido (DSC), microscopía de luz polarizada (PLM), viscosidad, difracción de rayos X por radiación de sincrotrón (SR-XRD) y espectroscopía FTIR. La calorimetría diferencial de barrido (DSC) midió las propiedades térmicas del oleogel de aceite de salvado de arroz y el oleogel rico en antioxidantes. Las imágenes de microscopía de luz polarizada revelaron una aguja como el cristal para RBW. Las medidas de SR-XRD se usaron para la clarificación de las estructuras cristalinas de los bloques de construcción de estos oleogeles. Se evaluaron las actividades antioxidantes de los oleogeles con ensayos de DPPH y ABTS.

PALABRAS CLAVE: Aceite de salvado de arroz; Cera de salvado de arroz; Oleogeles; RBOFAD; UMRBOFAD

ORCID ID: Sahu S https://orcid.org/0000-0002-9446-9584, Ghosh M https://orcid.org/0000-0002-7868-0785, Bhattacharyya DK https://orcid.org/0000-0001-7145-3654

Citation/Cómo citar este artículo: Sahu S, Ghosh M, Bhattacharyya DK. 2020. Utilization of the unsaponifiable matter from rice bran oil fatty acid distillate for preparing antioxidant-rich oleogel and evaluation of its properties. Grasas Aceites 71 (1), e336. https://doi.org/10.3989/gya.0938182

Copyright: (C2020 CSIC. This is an open-access article distributed under the terms of the Creative Commons Attribution 4.0 International (CC BY 4.0) License.

\section{INTRODUCTION}

Rice bran oil (RBO), a healthy vegetable oil, is a good source of various antioxidants such as oryzanol, tocopherol, tocotrienol, squalene and phytosterol and has greater oxidative stability and longer shelflife than other vegetable oils. Rice bran oil is a rich source of monounsaturated fatty acids (n-9 MUFA), n-6 PUFA and sterols, and it has been proven to reduce LDL (bad cholesterol). This healthy vegetable oil with a balanced fatty acid profile is more effective for preventing heart disease, skin disease, and cancer and it improves the immune system activity and neurological function (Ahmad Nayik et al., 2015).

Rice bran oil fatty acid distillate (RBOFAD) is a by-product which is produced in the physical refining plants for the de-acidification of RBO and this by-product is mainly utilized in soap manufacturing processes. Higher amounts of unsaponifiable matter composed of oryzanol, sterol, tocopherol, squalene and fatty alcohol are present in the rice bran oil fatty acid distillate (Sahu et al., 2018). Oryzanol, sterol, tocopherol, tocotrienol and squalene possess high antioxidant properties against free radicals (Ahmad Nayik et al., 2015). Oryzanol, an antioxidant compound in rice bran oil, decreases plasma cholesterol levels, serum cholesterol levels, and platelet aggregation with increasing bile excretion. Gamma oryzanol improves the immune system and good cholesterol levels, which is important for health. It prevents cancer and reduces menopause problems in women (Ahmad Nayik et al., 2015). Tocopherols and tocotrienols $(\alpha, \beta, \gamma$ and $\delta)$ are comprised in rice bran oil and are also important phytochemicals with antioxidant activities and potential health benefits (Chen and Bergman, 2005). The tocopherols in rice bran oil help to balance the endocrine hormones and improve neurological functions (Ahmad Nayik et al., 2015). Squalene, a phytochemical, has been studied for its preventive effects in many diseases such as cancer and cardiovascular diseases (Escrich et al., 2014). Recently, squalene has also received attention as a functional food in various food sectors. Studies have proven that phytosterols from plant origin have cholesterol-reducing activity (Gupta et al., 2011; Nijjar et al., 2010). Mixtures of phytosterols and $\gamma$-oryzanol are able to produce transparent gelling structures and other advantages of these components are the cholesterol reducing properties of Phytosterols (Calligaris et al., 2014; Dassanayake et al., 2011). Fatty alcohols are mainly derived from various vegetable oils and serve as raw material for making oleogel, which is recently gaining importance in bakery applications, various household products and surfactants (Dassanayake et al., 2011; Troni et al., 2013). Therefore, these constituents are useful for the utilization of functional foods for human health.

Ethylcellulose (EC), a hydrophobic polymer oleogelator has the ability of crystallization properties in edible oils and EC is commercially available, less expensive than other organogelators, and is also used as a food additive and textural modifier for oleogel formation in various food sectors (Gómez-Estaca et al., 2019; Hwang et al., 2013; Patel and Dewettinck 2015; Zetzl et al., 2014).

Waxes are esters of long chain fatty acids which are esterified to fatty alcohols; various hydrocarbon, ketones, fatty alcohols, mono-, di- and tri-acyleglycerol and sterol ester are contained in plant wax samples. These plant waxes have excellent crystallization properties in edible oils (Dassanayake et al., 2011). Studies have proven various plant wax crystallization in liquid oils such as rice bran wax in olive oil, sunflower wax in milk fat, animal wax and plant wax in sunflower oil and beeswax in hazelnut oil (Doan et al., 2015). Rice bran wax, a by-product of rice bran oil can be used as a good organogelator for valuable requirements in food sectors (Dassanayake et al., 2011). RBW has been used to provide certain micronutrients such as fatty alcohol, tocopherols, oryzanol, and sterols to act as an enhancer of oleogel formation besides providing nutritional quality and functional food properties such as antioxidants. 
The addition of RBW also enhanced the compatibility of ethyl cellulose in the oil phase along with the homogeneity of the ethyl cellulose based oleogel.

Oleogel is a colloidal system of microheterogeneous solid and liquid phase. In general, oleogels have a smooth texture with a small amount of gelator and they have shown feasibility for the replacement of trans and saturated fats containing hard stocks used in food products such as margarine, spreads, etc. (Hwang et al., 2013; Hwang et al., 2012). The mixture of oryzanol and phytosterols, wax esters, long chain fatty acids, fatty alcohols, waxes, lecithin, monoacylglycerides, sorbitan tristearate are more effective as organogelator for making oleogel from edible oil (Dassanayake et al., 2011).

The objective of the present investigation is mainly concerned with the utilization of high antioxidant-rich unsaponifiable matter, duly isolated from rice bran oil fatty acid distillate, as a composite organogelator system for making oleogels from rice bran oil along with rice bran wax or ethyl cellulose.

\section{MATERIALS AND METHODS}

\subsection{Materials and oleogel preparation}

RBOFAD and RBW, two refinery by-products, were obtained from M/S Sethia Oils Ltd. (Burdwan, WB, and India). Refined RBO was purchased from a local grocery store, ethyl cellulose (HIMEDIA, CAS no. 9004-57-3, RM 1610-500) was purchased from a reagent supplier and total unsaponifiable matter was isolated from RBOFAD following the standard AOAC method (AOAC 972.28). RBW was blended at $1-7 \mathrm{wt} \%$ levels with physically refined rice bran oil to produce oleogel. Antioxidant-rich, soft oleogel (gel A) was also produced with UMRBOFAD ( $2 \mathrm{wt}^{\mathrm{t}} \%$ ), ethyl cellulose ( $\left.2 \mathrm{wt} \%\right)$, RBW (3 wt \%) and
RBO. Oleogel (gel B) without the UMRBOFAD was prepared with only RBW and $\mathrm{RBO}$ at $80^{\circ} \mathrm{C}$ as shown in Table 1. Antioxidant-rich oleogel was prepared by dissolving the weighed solid ethyl cellulose, UMRBOFAD and RBW in rice bran oil (RBO) at $140{ }^{\circ} \mathrm{C}$ after full melting of all substances. Then the heated solution was cooled at room temperature $\left(26^{\circ} \mathrm{C}\right)$ and stored in the refrigerator and the oleogels are depicted in Figure 1.

\subsection{Oil binding capacity}

Oil binding capacity (OBC) is essential for one of the physical properties of oleogel (YIlmaz and Öğütcü 2014). First melted oleogel was put in an Eppendorf tube (a) which was previously weighed and stored in refrigerator for 1 hour. After that, this Eppendorf was again weighed (b) and centrifuged at $9000 \mathrm{rpm}$ at room temperature $\left(27-28{ }^{\circ} \mathrm{C}\right)$ for $16 \mathrm{~min}$. After centrifugation this Eppendorf was turned over onto a paper for draining the extra liquid oil. After the draining of the liquid oil, the Eppendorf tube was weighed again (c). OBC value was calculated by the equation:

$$
\begin{aligned}
& \text { Released oil }(\%)=[(b-a)-(c-a)] /(b-a) \times 100 \\
& \text { Oil binding capacity }(O B C) \%=100 \text { - released }
\end{aligned}
$$
oil $(\%)$

\subsection{Color measurement}

The colors of the surface of oleogel samples were mostly measured by Konica Minolta Color Reader CR 10 (Japan). The color was measured in three different points of each sample such as "L" (Lightness), "b+" (Yellowness) and "a+" (Redness) (Sahu et al., 2018).

TABLE 1. Composition of Gel A (Antioxidant-rich oleogel) and Gel B (Rice bran oil oleogel)

\begin{tabular}{lc}
\hline Antioxidant-rich oleogel (Gel A) & Components (\% Wt/Wt) \\
\hline Unsaponifiable matter of rice bran oil fatty acid distillate $(\mathrm{g} / 100 \mathrm{~g})$ & $3.92 \pm 0.10$ \\
$\gamma$-oryzanol (g/100g UM) & $3.15 \pm 0.14$ \\
total tocopherols (mg/100g UM) & $10.74 \pm 0.29$ \\
total phytosterol (g/100g UM) & $21.80 \pm 0.10$ \\
Squalene (g/100g UM) & $1.11 \pm 0.10$ \\
total fatty alcohol (g/100g UM) & $73.31 \pm 0.30$ \\
Rice bran wax (g/100g) & 3 \\
Ethyl cellulose (g/100g) & 2 \\
Refined rice bran oil (g/100g) & 93 \\
Rice bran oil oleogel (Gel B) & 7 \\
Rice bran wax $(\mathrm{g} / 100 \mathrm{~g})$ & 93 \\
Rice bran oil $(\mathrm{g} / 100 \mathrm{~g})$ & \\
\hline
\end{tabular}

Gel $A=$ Antioxidant-rich oleogel; Gel B = Rice bran oil oleogel, Each value is an average of three determinations, mean \pm SD. 
(a)

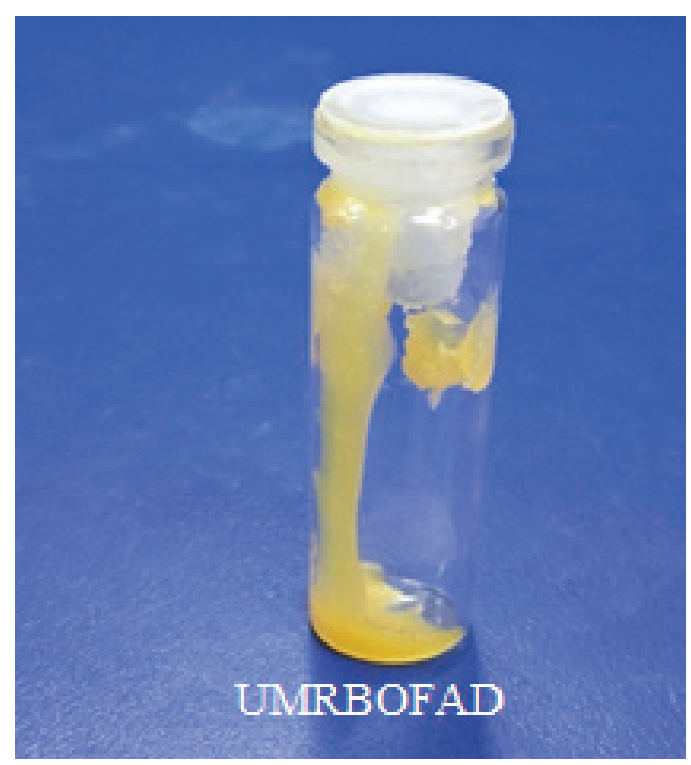

(b)

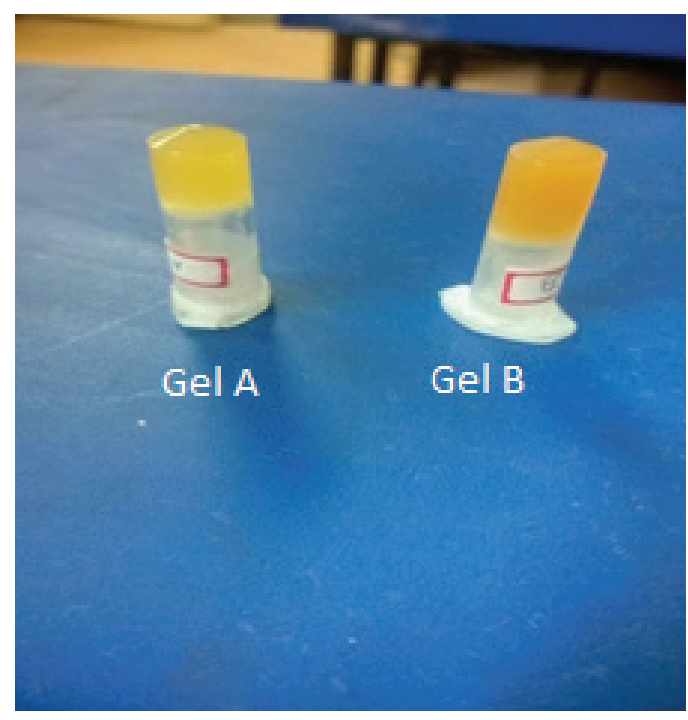

FIGURE 1. Pictures of (a) unsaponifiable matter of rice bran oil fatty acid distillate (UMRBOFAD) and (b) oleogel samples (Gel A; Antioxidant-rich oleogel \& Gel B; Rice bran oil oleogel).

\subsection{Thermal analysis}

The melting temperature and crystallization temperature of oleogel were examined by DSC (PerkinElmer Diamond DSC) (Dassanayake et al., 2011). Instrument calibration was done with Indium and Zinc. Each oleogel sample (20-25 mg) was weighed into an aluminium pan and hermetically sealed. The temperature was gradually increased from room temperature to $80{ }^{\circ} \mathrm{C}$ at $5{ }^{\circ} \mathrm{C} / \mathrm{min}$; the oleogel samples were cooled to $-20^{\circ} \mathrm{C}$ at $5{ }^{\circ} \mathrm{C} / \mathrm{min}$ and held for $3 \mathrm{~min}$ at $-20^{\circ} \mathrm{C}$ for full crystallization of the samples. Again these oleogel samples were heated to $80^{\circ} \mathrm{C}$ at $5{ }^{\circ} \mathrm{C} / \mathrm{min}$. because the antioxidant rich oleogel ( $\mathrm{Gel} \mathrm{A}$ ) was liquid at $80^{\circ} \mathrm{C}$ inspite of ethyl cellulose and rice bran wax being present due to the compatibility of ethyl cellulose in the gel, enhanced as revealed by the clarity of the oleogel.

\subsection{Crystal morphology}

The crystals of oleogel samples were observed by Polarized Light Microscope (Bin Sintang et al., 2017a). Small amounts of oleogel sample were placed on glass microscope slides and these slides were covered with glass cover slips. Partially and fully polarized digital images of various oleogels were observed using a camera (Canon) at room temperature. The crystal morphology of oleogel samples was compared at different concentrations of RBW, ethyl cellulose and UMRBOFAD.

\subsection{Viscosity measurements}

The viscosity of oleogel samples (gel A and gel B) was measured by a Viscometer (LR Lamy Rheology instrument). The oleogel samples were heated in water bath at $80^{\circ} \mathrm{C}$ for proper melting. These melted oleogel samples were placed in the sample cell of the viscometer and the viscosity was measured with a gradual decreasing of temperature $\left(80^{\circ} \mathrm{C}\right.$ to $20^{\circ} \mathrm{C}$ ) at the rate of $\sim 1 \%$ min. The viscosity measurements were plotted against the temperature.

\subsection{XRD analysis}

XRD patterns of oleogels were taken by Panalytical X'Pert PRO X-Ray diffractometer (Yang et al., 2017). Angular scans were performed from $2^{\circ}$ to $50^{\circ}$ at $2^{\circ} / \mathrm{min}$ scan rate with a copper source X-ray tube, $\alpha=1.54 \AA$.

\subsection{FTIR spectroscopy}

The oleogel samples were analyzed by Fourier transform infrared (FTIR) Spectroscopy (Perkin EImer FTIR) for infrared spectra measurements at $4000-650 \mathrm{~cm}^{-1}$ wave range (YIlmaz and Öğütcü, 2014).

\subsection{Oxidative stability}

Peroxide value measurements for the determination of the primary lipid oxidation of oleogel samples as an important determination for oxidative stability during the storage period of oleogels at 3 to $4{ }^{\circ} \mathrm{C}$ were made following the AOCS method (Ögütcü et al., 2015). The peroxide values (meq $\mathrm{O}_{2} \mathrm{Kg}^{-1}$ ) of oleogel samples were measured by the acetic acid-chloroform method and potassium iodide solution. 


\subsection{Determination of DPPH and ABTS+ radical scavenging activity}

The DPPH (1,1- diphenyl-2-picrylhydrazyl) was measured for the determination of radical scavenging power of oleogel samples. The samples were diluted to varying concentrations with isopropanol, and then these diluted samples were mixed with $1 \mathrm{ml}$ DPPH solution $(0.04 \mathrm{mg} / \mathrm{ml})$ in a dark place. The mixture was then incubated at room temperature $\left(28{ }^{\circ} \mathrm{C}\right)$ for $30 \mathrm{~min}$. The absorbance of solutions was measured at $517 \mathrm{~nm}$ using a spectrophotometer (JASCO V630 UV Vis Mississippi, USA). The sample concentration required for scavenging 50\% $\mathrm{DPPH}$ free radical $\left(\mathrm{IC}_{50}\right)$ was determined from the percent inhibition curve against the respective concentration (Pengkumsri et al., 2015).

The free radical scavenging activity of the oleogel samples was measured by the $\mathrm{ABTS}^{+}$radical. An ABTS $^{+}$stock solution was prepared by mixing with $\mathrm{ABTS}^{+}(7 \mathrm{mM})$ and potassium persulfate $(2.45 \mathrm{mM})$ and stored in the dark at room temperature for 16 hours. The $\mathrm{ABTS}^{+}$solution was diluted with ethanol (1:50) to obtain the perfect absorbance $(0.700 \pm 0.02)$ at $734 \mathrm{~nm} .10 \mu \mathrm{L}$ samples were diluted with isopropanol $190 \mu \mathrm{L}$ diluted $\mathrm{ABTS}^{+}$solutions were added. This solution was incubated at room temperature for $10 \mathrm{~min}$ and the absorbance was measured by a UV Spectrophotometer at $734 \mathrm{~nm}$. The free radical scavenging activity was determined by the $\mathrm{IC}_{50}$ value, which expresses the concentration of sample required for the inhibition of $50 \%$ radical (Pengkumsri et al., 2015).

\subsection{Statistical analysis}

The results were presented as mean values with standard deviations and the statistical analysis was done by the Tukey test $(\mathrm{p}<0.05)$ for the intergroup comparison of parametric data using Origin 8 software.

\section{RESULTS AND DISCUSSION}

\subsection{Physical properties of oleogels}

Some valuable physical characteristics of oleogels are shown in Table 2. The OBC value of gel A is much lower than that of gel $\mathrm{B}$. Therefore, gel $\mathrm{A}$ is a softer oleogel than gel B and gel B is a stronger, more stable gel than gel A (high antioxidant-rich oleogel). Gel A contained high amounts of unsaponifiable matter ( $\gamma$-oryzanol $3.27 \mathrm{~g} / 100 \mathrm{~g} \mathrm{UM}$; total tocopherol $10.93 \mathrm{mg} / 100 \mathrm{~g} \mathrm{UM}$; total phytosterol $21.81 \mathrm{~g} / 100 \mathrm{~g} \mathrm{UM}$; squalene $1.15 \mathrm{~g} / 100 \mathrm{~g} \mathrm{UM}$ and total fatty alcohol $73.34 \mathrm{~g} / 100 \mathrm{~g} \mathrm{UM}$ ) which is isolated from the rice bran oil fatty acid distillate (Sahu et al., 2018). Phytosterol and oryzanol mixture and fatty alcohol are good organogelators for making various types of oleogels (Dassanayake et al., 2011).

The colors of oleogels are different due to the presence of the unsaponifiable matter from rice bran fatty acid distillate, rice bran wax percentage and liquid stock oil. These colors of oleogels are usually dependent on rice bran wax concentration and used stock liquid oil because RBW consists of esters of long-chain saturated fatty acids and fatty alcohols (Yılmaz and Öğütcü 2014). "L" (Lightness) and " $\mathrm{b}+$ " (Yellowness) of antioxidant-rich oleogel (gel A) are much higher than gel B (without unsaponifiable matter) except "a+" (Redness) of gel A, as shown in Table 2.

\subsection{Thermal properties of oleogels}

Thermal parameters such as crystallization, melting temperatures and enthalpies of oleogel samples were measured by DSC and the results are shown in Table 3 . The crystal form of gel A began at $53.92^{\circ} \mathrm{C}$ and melting initiated at $57.37^{\circ} \mathrm{C}$. The peak temperature and peak crystallization temperatures were determined as 68.83 and $52.81{ }^{\circ} \mathrm{C}$. The melting enthalpy and crystallization enthalpy were $2.709 \mathrm{~J} / \mathrm{g}$ and $-0.303 \mathrm{~J} / \mathrm{g}$. The starting points of crystallization and the melting of gel $\mathrm{B}$ were at $53.91{ }^{\circ} \mathrm{C}$ and $68.13^{\circ} \mathrm{C}$. The peak melting and peak crystallization temperatures of gel B were observed at $68.13{ }^{\circ} \mathrm{C}$ and $51.88{ }^{\circ} \mathrm{C}$; crystallization and melting enthalpies were $-7.646 \mathrm{~J} / \mathrm{g}$ and $7.549 \mathrm{~J} / \mathrm{g}$. Crystallization and melting enthalpy values were high because gel B contained a higher amount RBW than gel A because the concentration of RBW was smaller in gel A compared to gel B. In general, the peak and onset of melting and crystallization temperatures of oleogel A (high antioxidant rich) were quite similar to oleogel B. The differences in onset and peak temperatures can be attributed to the relatively higher melting points of the constituents of unsaponifiable

TABLE 2. Physical properties of prepared oleogels

\begin{tabular}{lcccc}
\hline Samples & OBC $(\%)$ & $\mathbf{L}$ & $\mathbf{a}^{*}$ & $\mathbf{b}^{*}$ \\
\hline$G e l A$ & $38.71 \pm 0.17^{\mathrm{a}}$ & $42.53 \pm 0.05^{\mathrm{a}}$ & $+3.86 \pm 0.05^{\mathrm{a}}$ & $+8.26 \pm 0.15^{\mathrm{a}}$ \\
$\mathrm{Gel} B$ & $72.06 \pm 0.07$ & $38.60 \pm 0.26$ & $+0.90 \pm 0.10$ & $+0.96 \pm 0.20$ \\
\hline
\end{tabular}

Gel $A=$ Antioxidant-rich oleogel; Gel $B=$ Rice bran oil oleogel; $O B C=$ oil binding capacity; $L, a *, b *$ instrumental color parameters. Each value is an average of three determinations, mean $\pm S D$. At $p<0.05$, significant differences are shown by symbol " $a$ ". 
TABLE 3. Thermal properties of oleogels

\begin{tabular}{|c|c|c|c|c|c|c|}
\hline \multirow[b]{2}{*}{ Samples } & \multicolumn{3}{|c|}{ Crystallization } & \multicolumn{3}{|c|}{ Melting } \\
\hline & Onset $\left({ }^{\circ} \mathrm{C}\right)$ & Peak $\left(\mathrm{T},{ }^{\circ} \mathrm{C}\right)$ & $\Delta H(J / g)$ & Onset $\left({ }^{\circ} \mathrm{C}\right)$ & Peak $\left(T,{ }^{\circ} \mathrm{C}\right)$ & $\Delta H(J / g)$ \\
\hline Gel A & $53.92 \pm 0.00^{\mathrm{ns}}$ & $52.80 \pm 0.00^{\mathrm{a}}$ & $-0.303 \pm 0.00^{\mathrm{a}}$ & $57.37 \pm 0.00^{\mathrm{a}}$ & $63.82 \pm 0.00^{\mathrm{a}}$ & $2.705 \pm 0.00^{\mathrm{a}}$ \\
\hline Gel B & $53.91 \pm 0.00$ & $51.88 \pm 0.01$ & $-7.646 \pm 0.00^{\mathrm{a}}$ & $60.54 \pm 0.01$ & $68.11 \pm 0.01$ & $7.546 \pm 0.00$ \\
\hline
\end{tabular}

Gel $A=$ Antioxidant-rich oleogel; Gel B = Rice bran oil oleogel. Each value is an average of three determinations, mean $\pm S D$. At $p<0.05$, significant differences are shown by symbol " $a$ ". $n s=$ Not significant .

matter such as oryzanol, phytosterol and fatty alcohol. Antioxidant-rich oleogel (Gel A) became liquid at $80{ }^{\circ} \mathrm{C}$ inspite of containing Ethyl cellulose and rice bran wax, presumably due to the compatibility of ethyl cellulose and wax in the oil phase of the oleogel, which was further accentuated in particular by the action of oryzanol as a solutizer. Therefore, gel A could be better as a good food application than gel B because gel A contained higher amounts of unsaponifiable matters ( $\gamma$-oryzanol, tocopherol, squalene, phytosterol and fatty alcohol). The composition of unsaponifiable matter can be utilized in food products such as margarine, mayonnaise, health drinks, bakery products such as biscuits and cakes where the unsaponifiable matter constituents act as good antioxidants, preserving the flavor characteristics of the baked products by maintaining the oxidative stability of the fat phases.

\subsection{Crystal morphological properties}

The crystal morphological properties of the two oleogels (gel A and gel B) were found by Polarized Light Microscope (PLM) and are depicted in Figure 2. These pictures show the morphological structure of oleogels with rice bran wax and unsaponifiable matter from rice bran fatty acid distillate and reveal that the crystallized form of gel B is similar to gel A, which is a more antioxidant-rich oleogel. Literature reviews of oleogels with rice bran wax showed more needle-like structure (Doan et al., 2015). The results for the morphological properties of oleogels showed a smooth and homogeneous mixture of oleogels. From this study, it was determined that gel A was smooth and homogeneous, similar to gel $\mathrm{B}$ and gel $\mathrm{B}$ contained a more needle-like structure than gel A, although gel A contained large needle crystals and network-like structure because gel A contains higher amounts of oryzanol, phytosterol and ethyl cellulose (Bin Sintang et al., 2017a).

\subsection{The viscosity of oleogel samples}

The viscous properties of the oleogel samples (gel $\mathrm{A}$ and gel $\mathrm{B}$ ) during the cooling process are shown in Figure 3. The viscosity of gel B with RBW at $7 \% \mathrm{~W} / \mathrm{W}$ ) was higher than gel A during the cooling process because gel B contained a high amount of (a)

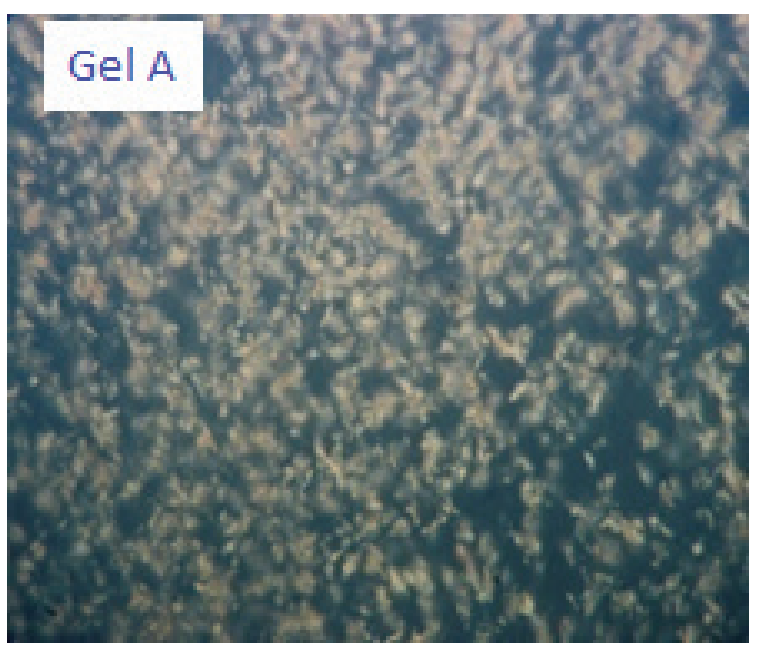

(b)

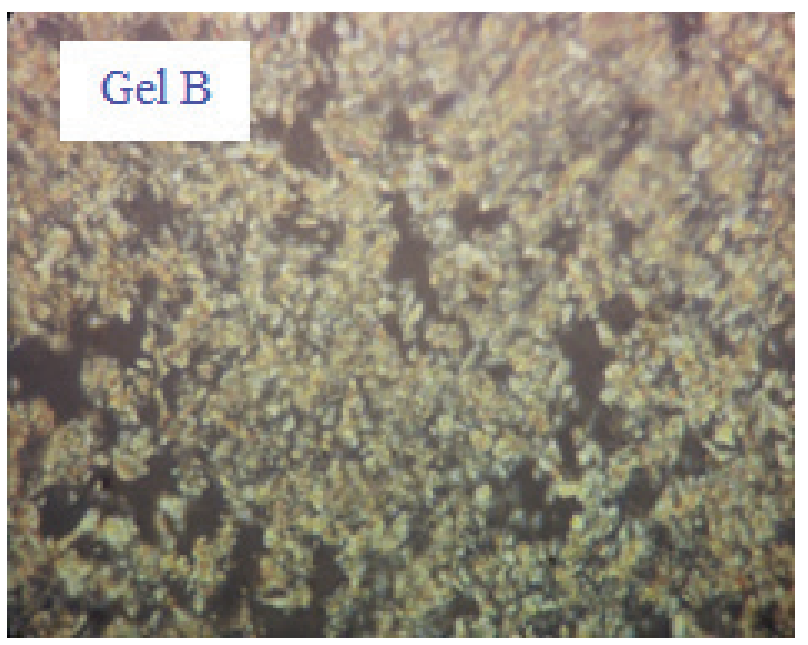

FIgURE 2. Polarized Light Microscopy (PLM) pictures of oleogel samples (a) Gel A; Antioxidant-rich oleogel and (b) Gel B; Rice bran oil oleogel); Gel B with rice bran wax (7 Wt.\%) and Gel A with rice bran wax (3 Wt.\%), ethyl cellulose (2 Wt.\%) and Unsaponifiable matter of rice bran oil fatty acid distillate (2 Wt.\%).

rice bran wax which created a more fiber-like needle crystal structure and formed a strong gel structure. The viscosity of the oleogel samples was explained by temperature, crystallization, size and shape. 


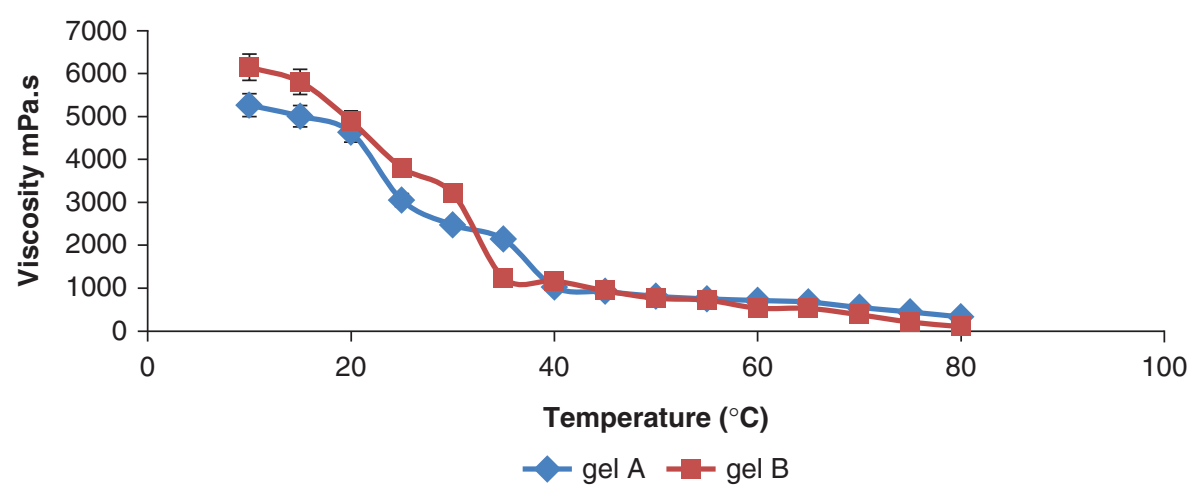

FIGURE 3. Viscosity properties of oleogel samples (gel A; Antioxidant-rich oleogel and gel B; Rice bran oil oleogel) during the cooling process of oleogel. Each value is an average of three determinations, mean \pm SD. Error bars represent standard deviations of values and each value is significantly different at $p<0.05$ according to the Tuky test.

\subsection{X- ray diffraction patterns of oleogel samples}

The x-ray diffraction (XRD) patterns of the oleogel samples were measured and the results are shown in Table 4 and Figure 4. The XRD patterns of gel $\mathrm{A}$ and gel $\mathrm{B}$ were very similar according to Figure 3. The peaks for gel $\mathrm{A}$ in the wide-angle region were at around $3.73 \AA-4.50 \AA$ and the wide-angle region peaks for gel $\mathrm{B}$ were at around $3.71 \AA-4.51 \AA$ (Table 4). Wide angle region peaks for bee wax gel and carnauba gel were very similar at around $3.73 \AA-4.60 \AA$ (CB7); $3.73 \AA-4.59 \AA$ (CC7) (Yllmaz \& Öğütcü 2014). Gel A contained higher amounts of phytosterol, oryzanol and fatty alcohol than gel $\mathrm{B}$. The high intensity of short spacing peaks of oleogel sample A was due to the combination of various gelators such as phytosterol, fatty alcohol, oryzanol and ethyl cellulose (Dassanayake et al., 2011; Stortz and Marangoni 2014; Yang et al., 2017; Zetzl et al., 2014), which indicated a lateral packing of molecular layers. Gel B, with single gelator, presented self-shorting and rearrangement of gelator molecules because of its high intensity of long spacing peaks. In this study, the XRD diffraction of gel A was observed with peaks of RBW, UMRBOFAD and EC crystals in the $\beta$ ' polymorphic form.

TABLE 4. X-ray diffraction patterns of oleogels

\begin{tabular}{lcc}
\hline Samples & 2- theta & d (̊̊) \\
\hline Gel $A$ & $19.29,21.45,23.80$ & $4.50,4.13,3.73$ \\
Gel $B$ & $19.64,21.60,23.95$ & $4.51,4.10,3.71$ \\
\hline
\end{tabular}

Oleoel A = Antioxidan- rich oleogel; Gel B = Rice bran oil oleogel.

(a)

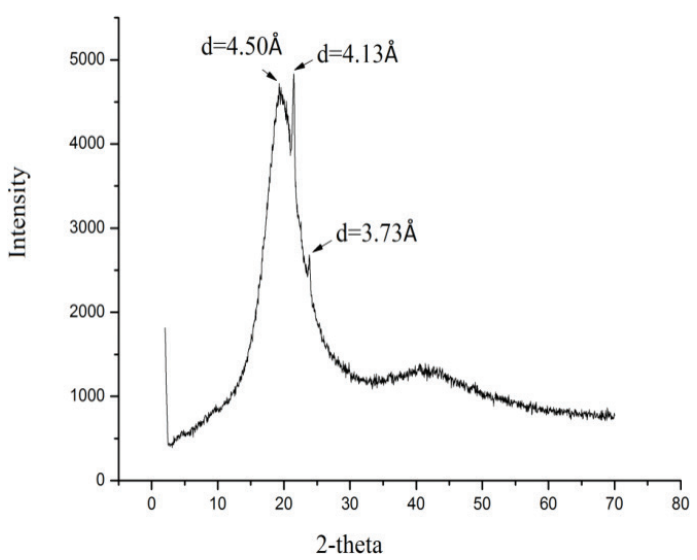

(b)

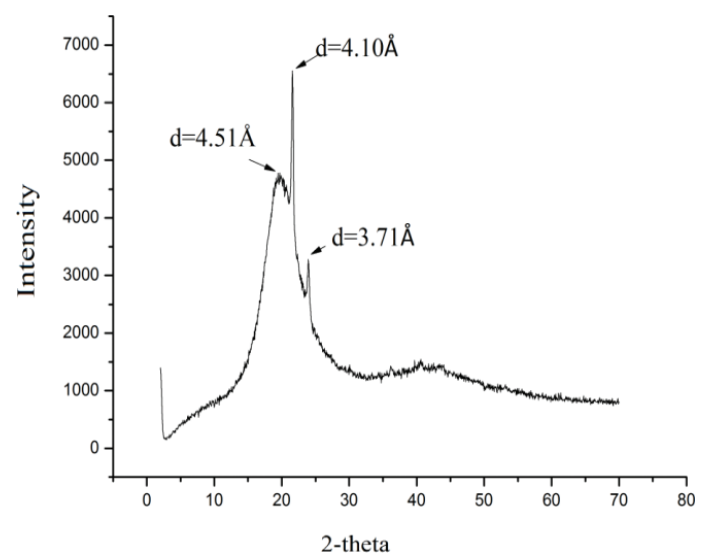

Figure 4. X-ray diffraction patterns of oleogels (A) Gel A; Antioxidant-rich oleogel and (B) Gel B; Rice bran oil oleogel. 


\subsection{The FTIR spectra of oleogel samples}

The FTIR spectra of the oleogel samples (gel $\mathrm{A}$ and gel B) are shown in Figure 5. The hydrogen bond formation between the molecules of the oleogel samples was analyzed by FTIR spectroscopy, which covered a $4000-650 \mathrm{~cm}^{-1}$ wave range. This analysis provided information about the interaction of molecules in the oleogel samples. In view of the molecular nature of the various components present in the two oleogels, the IR spectrum was expected to be almost identical, with peaks at nearly the same wave lengths as indicated in the FTIR spectra. There was a spectral difference between gel A (more antioxidant-rich oleogel) and gel $\mathrm{B}$ at around $3,215-3,520 \mathrm{~cm}^{-1}$. The FTIR spectra measurement of the $\beta$-sitosterol and $\gamma$-oryzanol-based organogel was seen at around $3,441 \mathrm{~cm}^{-1}$, which was observed in sitosterol slurry as an intermolecular hydrogen bond (Yılmaz and Ögütcü 2014). Gel A sample contained higher amounts of phytosterol and oryzanol than gel B; the FTIR spectral measurement of gel A was observed as medium-intensity band at around
$3,385-3,520 \mathrm{~cm}^{-1}$ due to the presence of high amounts of phytosterol and oryzanol. This mixture of phytosterol and oryzanol in gel A had a highly specific intermolecular hydrogen bond (Yilmaz and Ögütcü 2014).

\subsection{Oxidative stability of oleogel samples}

The results on the oxidative stability of the oleogel samples were more significant for storage stability from 0 day to 90 days at two different temperatures such as room temperature $\left(26^{\circ} \mathrm{C}\right)$ and refrigerator temperature $\left(4^{\circ} \mathrm{C}\right)$, as shown in Figure 6. There were slight differences in peroxide value (PV) between room temperature and refrigerator temperature because the oleogels were produced from stable edible oil. Figure 6 clearly demonstrates that the peroxide value for the oleogel samples stored at room temperature was always higher than the oleogel sample stored at refrigerator temperature, which was also reported previously (Ö̈̆̈̈tcü et al., 2015; Yilmaz and Öğ̈utcü 2014). On day 0 , the peroxide values of gel $\mathrm{A}$ and gel $\mathrm{B}\left(0.50 \mathrm{meq} \mathrm{O}_{2} \cdot \mathrm{Kg}^{-1}\right.$ and

(a)

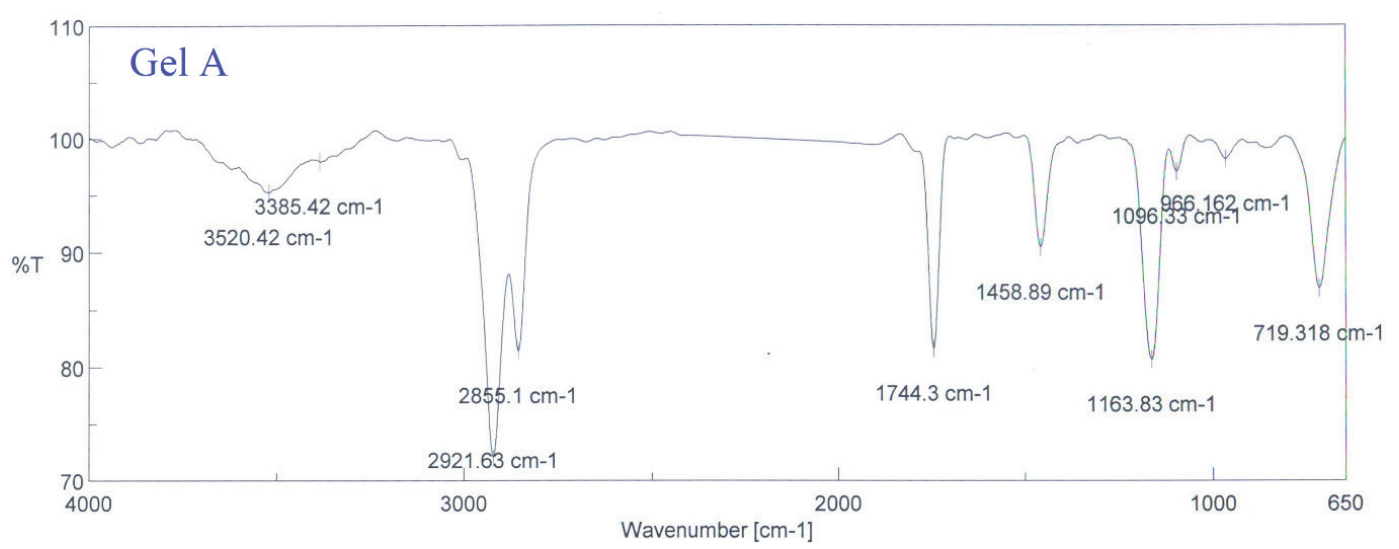

(b)

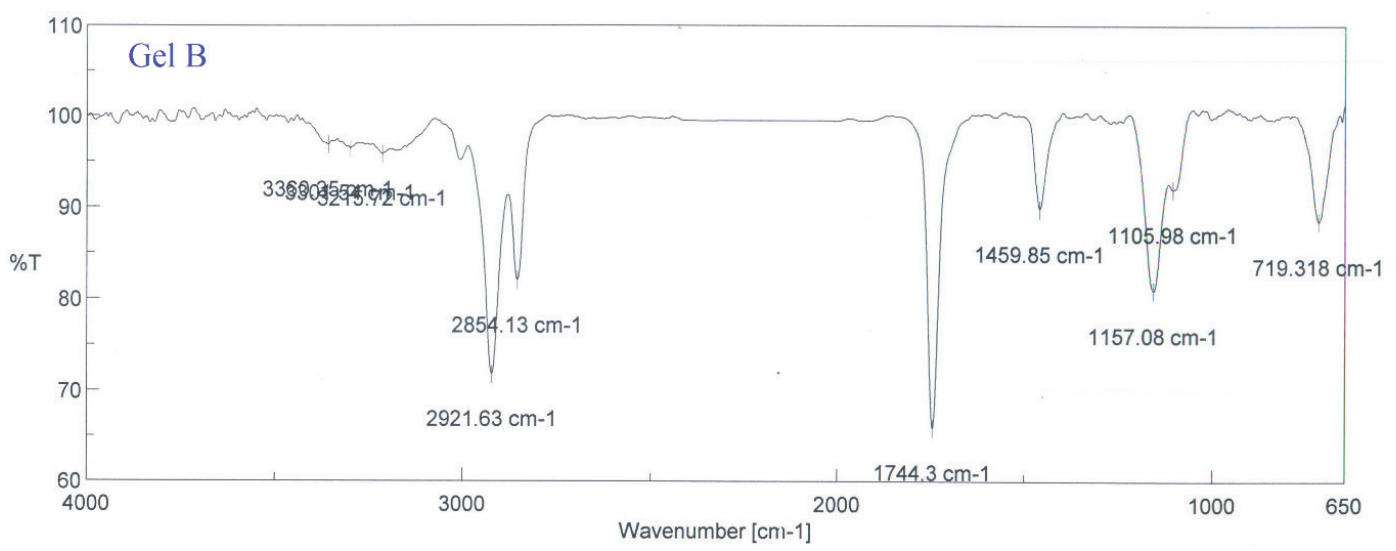

Figure 5. The FT-IR Spectra of oleogel samples (a) Gel A; Antioxidant-rich oleogel and (b) Gel B; Rice bran oil oleogel. 
(a)

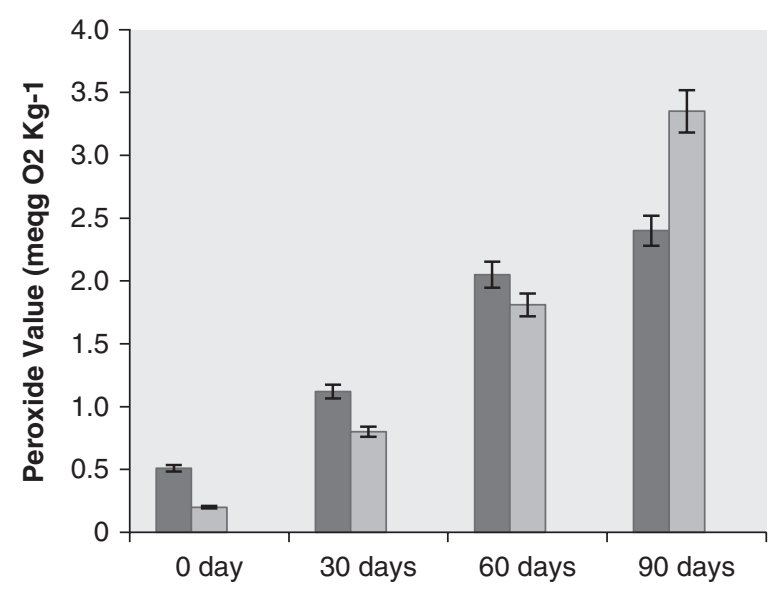

(b)

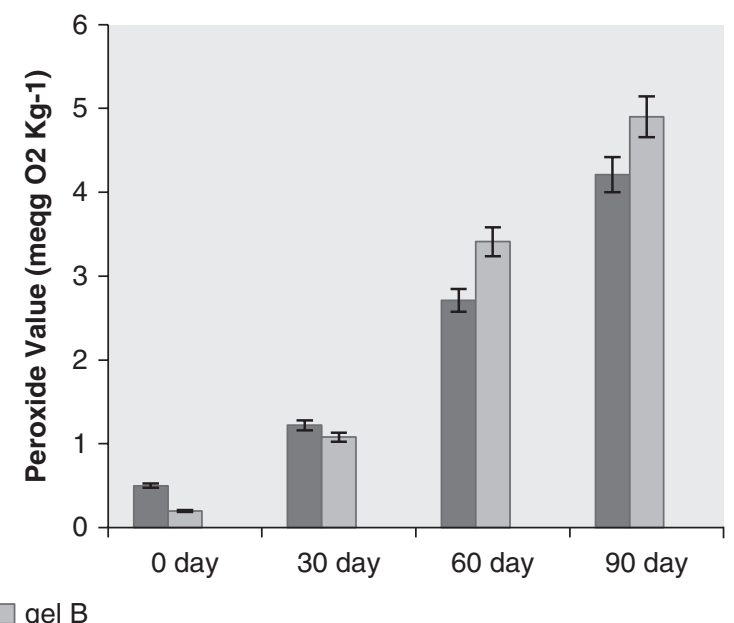

FIGURE 6. The peroxide values of oleogel samples at (a) refrigerator temperature $\left(4^{\circ} \mathrm{C}\right)$ and $(\mathbf{b})$ room temperature $\left(26^{\circ} \mathrm{C}\right)$. Each value is an average of three determinations, mean \pm SD. Error bars represent standard devietions of values and each value is significantly different at $p<0.05$ according to the Tuky test.

0.20 meq $\mathrm{O}_{2} \cdot \mathrm{Kg}^{-1}$ ) were observed and after 90 days the PV values of stored gel $\mathrm{A}$ and gel $\mathrm{B}$ sample were determined $\left(2.50 \mathrm{meq} \mathrm{O}_{2} \cdot \mathrm{Kg}^{-1}\right.$ and $3.25 \mathrm{meq}$ $\left.\mathrm{O}_{2} \cdot \mathrm{Kg}^{-1}\right)$ at room temperature. Similarly, the peroxide value $\left(4.25 \mathrm{meq} \mathrm{O}_{2} \cdot \mathrm{Kg}^{-1}\right)$ of gel A sample was slightly lower when stored for 90 days than gel B $\left(5 \mathrm{meq} \mathrm{O}_{2} \cdot \mathrm{Kg}^{-1}\right)$ at refrigerator temperature because gel $\mathrm{A}$ is rich in tocopherols, which is an important phytochemical for the prevention of lipid peroxidation for the storage stability of vegetable oils (Ahmad Nayik et al., 2015; Chen and Bergman 2005).

\subsection{DPPH and ABTS+ free radical scavenging activity}

The antioxidant properties of the oleogel samples were evaluated through DPPH and $\mathrm{ABTS}^{+}$ radical scavenging activity as shown in Table 5. These radical scavenging activities were explained as $\mathrm{IC}_{50}$ Value, which is the required sample concentration for $50 \%$ inhibition of radicals (Jayathilake et al., 2016; Li et al., 2009; Pengkumsri et al., 2015). The DPPH radical-scavenging activity of

TABle 5. Antioxidant activity $\left(\mathrm{IC}_{50}\right)$ of oleogels $(\mathrm{Gel} \mathrm{A}$; Antioxidant-rich oleogel and Gel B; Rice bran oil oleogel); DPPH radical-scavenging activity and $\mathrm{ABTS}^{+}$radicalscavenging activity

\begin{tabular}{lcc}
\hline Antioxidant capacity & Gel B & Gel A \\
\hline DPPH assay $(\mathrm{mg} / \mathrm{ml})$ & $1.916 \pm 0.104$ & $1.156 \pm 0.081^{\mathrm{a}}$ \\
ABTS assay $(\mathrm{mg} / \mathrm{ml})$ & $0.059 \pm 0.006$ & $0.051 \pm 0.010^{\mathrm{ns}}$ \\
\hline
\end{tabular}

Gel $A=$ Antioxidant-rich oleogel; Gel B = Rice bran oil oleogel. Each value is an average of three determinations, mean $\pm S D$. At $p<0.05$, significant differences are shown by symbol " $a$ ". $n s=$ Not significant . gel A was higher $\left(\mathrm{IC}_{50}\right.$ Value $\left.=1.156 \mathrm{mg} / \mathrm{ml}\right)$ than gel $\mathrm{B}\left(\mathrm{IC}_{50}\right.$ Value $\left.=1.916 \mathrm{mg} / \mathrm{ml}\right)$ and similarly the $\mathrm{ABTS}^{+}$scavenging activity of gel A was significantly higher $\left(\mathrm{IC}_{50}\right.$ Value $\left.=0.051 \mathrm{mg} / \mathrm{ml}\right)$ compared to gel $\mathrm{B}\left(\mathrm{IC}_{50}\right.$ Value $\left.=0.059 \mathrm{mg} / \mathrm{ml}\right)$ because gel A contained higher amounts of unsaponifiable matter ( $\gamma$-oryzanol, tocopherols, sterols, squalene and fatty alcohol) which is isolated from the rice bran fatty acid distillate. Antioxidant activity and storage stability declined slightly during storage even though more antioxidants like tocopherols, oryzanol, squalene and phytosterol were present in gel A, which prevents the lipid oxidation of oleogels.

\section{CONCLUSIONS}

The present work clearly demonstrates that the unsaponifiable matters of rice bran oil fatty acid distillate (UMRBOFAD) can be gainfully utilized as an antioxidant-rich mixed gelator for making antioxidant enriched oleogel from refined rice bran oil, rice bran wax or ethyl cellulose as bulk organic phase. The oleogel products have the desired composition, morphological structure, thermal properties, viscosity, X-Ray diffraction properties, antioxidant activities and storage stabilities. Antioxidant-rich oleogels have antioxidant activity, shelf-life and cholesterol lowering capacity. They are more stable products and have better shelf-life during storage due to the antioxidant contents derived from the unsaponifiable matter from the rice bran oil fatty acid distillate. The antioxidant-rich oleogel is very important for a PUFA-rich margarine product and also for preparing healthy margarine for reducing blood cholesterol due to the presence of oryzanol, tocopherols, squalene and phytosterols. 


\section{ACKNOWLEDGMENT}

The authors acknowledge the School of Community Science and Technology, Indian Institute of Engineering, Science and Technology, Shibpur, Howrah for providing the necessary facilities.

\section{REFERENCES}

Ahmad Nayik G, Majid I, Gull A, Muzaffar K. 2015. Rice bran oil, the future edible oil of India: A mini Review. Rice Res. Open Access 03, 1-3. https://doi.org/10.4172/2375-4338. 1000151

Bin Sintang MD, Rimaux T, Walle DV, Dewettinck K, Patel AR. 2016. Oil structuring properties of monoglycerides and phytosterols mixtures. Eur. J. Lipid Sci. Technol. 119, 1500517. https://doi.org/10.1002/ejlt.201500517

Calligaris S, Mirolo G, Pieve SD, Arrighetti G, Nicoli MC. 2013. Effect of Oil Type on Formation, Structure and Thermal Properties of $\gamma$-oryzanol and $\beta$-sitosterol-Based Organogels. Food Biophys. 9, 69-75. https://doi.org/10.1007/ s11483-013-9318-z

Chen M-H, Bergman CJ. 2005. A rapid procedure for analysing rice bran tocopherol, tocotrienol and g-oryzanol contents. J. Food Compos. Anal. 18, 139-151. https://doi.org/10.1016/j. jfca.2003.09.004

Dassanayake LSK, Kodali DR, Ueno S. 2011. Formation of oleogels based on edible lipid materials. Curr. Opin. Colloid Interface Sci. 16, 432-439. https://doi.org/10.1016/j. cocis. 2011.05.005

Doan CD, Walle DV, Dewettinck K, Patel AR. 2015. Evaluating the Oil-Gelling Properties of Natural Waxes in Rice Bran Oil: Rheological, Thermal, and Microstructural Study. J. Am. Oil Chem. Soc. 92, 801-811. https://doi.org/10.1007/ s11746-015-2645-0

Escrich E, Solanas M, Moral R. 2014. Olive Oil and Other Dietary Lipids in Breast Cancer. in Cancer Treatment and Research. Advances in Nutrition and Cancer 31, 289-309. https://doi.org/10.1007/978-3-642-38007-5 17

Gómez-Estaca J, Herrero AM, Herranz B, Alvarez MD, Jimenez-Colmenero F, Cofrades S. 2019. Characterization of ethyl cellulose and beeswax oleogels and their suitability as fat replacers in healthier lipid pâtés development. Food Hydrocoll. 87, 960-969. https://doi.org/10.1016/j. foodhyd.2018.09.029

Gupta AK, Savopoulos CG, Ahuja J, Hatzitolios AI. 2011. Role of phytosterols in lipid-lowering: current perspectives. QJM 104, 301-308. https://doi.org/10.1093/qjmed/hcr007

Hwang H-S, Singh M, Bakota EL, Winkler-Moser JK, Kim S, Liu SX. 2013. Margarine from Organogels of Plant Wax and Soybean Oil. J. Am. Oil Chem. Soc. 90, 1705-1712. https://doi.org/10.1007/s11746-013-2315-z
Hwang H-S, Kim S, Singh M, Winkler-Moser JK, Liu SX 2011. Organogel Formation of Soybean Oil with Waxes. $J$. Am. Oil Chem. Soc. 89, 639-647. https://doi.org/10.1007/ s11746-011-1953-2

Jayathilake C, Rizliya V, Liyanage R. 2016. Antioxidant and Free Radical Scavenging Capacity of Extensively Used Medicinal Plants in Sri Lanka. Procedia Food Sci. 6, 123-126. https://doi.org/10.1016/j.profoo.2016.02.028

Li X, Wu X, Huang L. 2009. Correlation between Antioxidant Activities and Phenolic Contents of Radix Angelicae Sinensis (Danggui). Molecules 14, 5349-5361. https://doi. org/10.3390/molecules 14125349

Nijjar PS, Burke FM, Bloesch A, Rader DJ. 2010. Role of dietary supplements in lowering low-density lipoprotein cholesterol: A review. J. Clin. Lipidol. 4, 248-258. https:// doi.org/10.1016/j.jacl.2010.07.001

Öğütcü M, Arifoğlu N, Yilmaz E. 2015. Storage stability of cod liver oil organogels formed with beeswax and carnauba wax. Int. J. Food Sci. Technol. 50, 404-412. https://doi.org/ 10.1111/ijfs. 12612

Patel AR, Dewettinck K. 2015. Comparative evaluation of structured oil systems: Shellac oleogel, HPMC oleogel, and HIPE gel. Eur. J. Lipid Sci. Technol. 117, 1772-1781. https://doi.org/10.1002/ejlt.201400553

Pengkumsri N, Chaiyasut C, Sivamaruthi BS, Saenjum C, Sirilun S, Peerajan S, Suwannalert P, Sirisattha S, Chaiyasut K, Kesika P. 2015. The influence of extraction methods on composition and antioxidant properties of rice bran oil. Food Sci. Technol. 35, 493-501. https://doi.org/10.1590/ 1678-457X.6730

Sahu S, Ghosh M, Bhattacharyya DK. 2018. Isolation of the unsaponifiable matter (squalene, phytosterols, tocopherols, $\gamma$-oryzanol and fatty alcohols) from a fatty acid distillate of rice bran oil. Grasas Aceites 69, e262. https://doi. org/10.3989/gya.1112172

Stortz TA, Marangoni AG. 2014. The replacement for petrolatum: Thixotropic ethylcellulose oleogels in triglyceride oils. Green Chem. https://doi.org/10.1039/c4gc00052h

Troni KL, Silva SM, Meirelles AJA, Ceriani R. 2013. Study of Fatty Acid and Fatty Alcohol Formation from Hydrolysis of Rice Bran Wax. Chem. Eng. Trans. 32, 1747-1752. https://doi.org/10.3303/CET1332292

Yang S, Li G, Saleh ASM. 2017. Functional Characteristics of Oleogel Prepared from Sunflower Oil with $\beta$-Sitosterol and Stearic Acid. J. Am. Oil Chem. Soc. 94, 1153-1164. https:// doi.org/10.1007/s11746-017-3026-7

Yılmaz E, Öğütcü M. 2014. Properties and Stability of Hazelnut Oil Organogels with Beeswax and Monoglyceride. J. Am. Oil Chem. Soc. 91, 1007-1017. https://doi.org/10.1007/ s11746-014-2434-1

Zetzl AK, Gravelle AJ, Kurylowicz M, Dutcher J, Barbut S, Marangoni AG. 2014. Microstructure of ethylcellulose oleogels and its relationship to mechanical properties. Food Struct. 2, 27-40. https://doi.org/10.1016/j.foostr.2014.07.002 